\title{
Involutional Lower Eyelid Entropion: Combined Wheeler's and Wedge Resection of Tarsal Plate
}

\author{
Involutional Basse-Entropion paupières: Wheeler combinée et résection cunéiforme du tarse
}

\author{
C. Olali*, V. Burton ${ }^{\dagger}$, E. Samaila*
}

\begin{abstract}
BACKGROUND: Involutional entropion, a common eyelid condition, has different methods of surgical correction and attendant variable recurrence rates, depending to a large degree on the method used.

OBJECTIVE: To describe and evaluate a modified technique of entropion repair where the Wheeler's method is combined with wedge resection of the tarsal plate.

METHODS: This was a chart review study of 49 patients who had the modified technique carried out to correct their involutional entropion. The technique essentially involves dissecting and separating the lower lid pre-tarsal orbicularis muscle from the tarsal plate, resecting a down-base triangular wedge of the tarsus followed by shortening the orbicularis and anchoring it to the tarsal plate superiorly.

RESULTS: Over the three and a half-year review period, 54 eyelids of 49 patients underwent the procedure to correct their lower eyelid entropion. Of these, $28(57 \%)$ were females and $\mathbf{2 1}(\mathbf{4 3} \%$ ) males with a mean age of 73.5 years. The mean follow up period was 30.3 months. One $(1.9 \%)$ recurrence was recorded in all the cases during the follow-up period. Complications were minimal.

CONCLUSION: The combined Wheeler and wedge resection of the tarsal plate produces very good post-operative results and can be used in primary involutional entropion or as the procedure of choice if an initial different surgical technique used fails. WAJM 2010; 29(2): 117-119.
\end{abstract}

Keywords: Entropion, recurrence rate, wedge resection, wheeler technique.

\section{RÉSUMÉ}

CONTEXTE: entropion involutif, une paupière condition commune, a différentes méthodes de correction chirurgicale et de préposé taux de récidive variable, en fonction dans une large mesure sur la méthode utilisée.

OBJECTIF: décrire et évaluer une technique de modification de la réparation entropion où Wheeler la méthode est combinée avec résection cunéiforme du tarse.

MÉTHODES: Il s'agissait d'une étude de l'examen des dossiers de 49 patients qui avaient la technique de modification effectuée pour corriger leurs entropion involutif. La technique consiste essentiellement à disséquer et à séparer la paupière inférieure pré-tarsienne muscle orbiculaire de la plaque du tarse, la résection d'un coin à base triangulaire vers le bas du tarse suivie par un raccourcissement du muscle orbiculaire et l'ancrer à l'tarse haut.

RÉSULTATS: Au cours des trois ans et demi la période d'examen, 54 paupières des 49 patients ont subi la procédure pour corriger leur faible entropion de la paupière. Parmi eux, 28 (57\%) étaient des femmes et 21 (43\%) des hommes avec un âge moyen de 73,5 ans. La moyenne période de suivi était de 30,3 mois. Un (1,9\%) récidive a été enregistrée dans tous les cas au cours de la période de suivi en place. Les complications ont été minimes.

CONCLUSION: La combinaison Wheeler et résection cunéiforme du tarse produit de très bons résultats postopératoires et peut être utilisé dans entropion involutif primaire ou que la procédure de choix si une technique chirurgicale initiale différents utilisés échoue. WAJM 2010; 29 (2): 117-119.

Mots-clés: Entropion, le taux de récidive, résection cunéiforme, technique Wheeler.

* Royle Eye Department, Pilgrim Hospital, Boston, PE21 9QS, England, Ophthalmology, Bassetlaw General Hospital, Worksop S81 0BD, England. Ophthalmology, Ahmadu Bello Teaching University Hospital, Zaria, Nigeria.

Correspondence: Dr. C. Olali, E-mail: akikio771@ hotmail.com 


\section{INTRODUCTION}

Involutional entropion is of multifactoral aetiology and because of this there is no generally agreed surgical technique for its correction. Rather many techniques are in use with varying recurrence rates in an attempt to correct the various aetiological factors. Horizontal lower lid laxity, orbicularis muscle override and lower retractor dehiscence play prominent roles in the causation of this problem, hence most of the techniques are aimed at correcting these. Hedin ${ }^{1}$ compared the results of simultaneous lower lid retractor tightening and horizontal lid shortening with lid only lid retractor tightening and found that recurrence occurred only with the later procedure. Weiss ${ }^{2}$ combined a full-thickness blepharotomy with rotation stitches but this has a high (> 22\%) recurrence rate, especially if there is considerable horizontal lid laxity. However, this method still remains in use in the treatment of entropion. ${ }^{3}$ The horizontal lid laxity could be corrected with a tarsal strip procedure or fullthickness eyelid resection. ${ }^{4,5}$ Joseph $e t$ $a l^{6}$ in a review of 63 cases where the modified concrib (inverted $\mathrm{T}$ ) procedure was used reported no recurrence after a median follow-up of 49.3 months.

In 1985, HSU and $\mathrm{LIU}^{7}$ described their new technique of correction of involutional entropion which involved fixation of a strip of dissected and displaced pre-tarsal orbicularis muscle. They described this technique as successful with an average follow-up of 12 months on 112 patients.

We describe a procedure somewhat similar to the above but with added wedge resection of the tarsal plate to treat involutional entropion and present the results of three and a half-year follow-up study of patients who underwent the procedure in our centre.

\section{Surgical Technique}

Local anaesthesia is performed with $2.5 \mathrm{ml}$ each of Lignocaine $2 \%$ + adrenaline $(1: 200,000)$ and Bupivacaine $0.5 \%$ (total $5 \mathrm{ml})$, with a small amount given first $(1 \mathrm{ml})$ and the rest 3-5minutes later to minimise any discomfort to the patient.

A transverse skin incision is made $2 \mathrm{~mm}$ below the lid margin, involving two- thirds of the lid. The orbicularis muscle is exposed and is dissected up to the lid margin. A muscle strip about $5 \mathrm{~mm}$ wide is fashioned from the superior margin and cut in the middle after inserting two 6/0 vicryl sutures as shown (See Figure). The two ends are drawn apart to expose the tarsal plate.

A base down triangular wedge of the tarsal plate is then resected centrally, with the base measuring about $3 \mathrm{~mm}$. The tarsal plate is then sutured end to end with two interrupted $6 / 0$ vicryl sututres. The orbicularis strips are then overlapped and tied and the excess muscle cut. The superior margin of the overlapped muscle is then anchored to the tarsal plate with the same suture to prevent overriding. The skin is sutured with 7/0 black silk (Figure 1.11-12).

This technique of entropion repair was used in 49 patients during the period and data analysis based on the outcome. The procedure was carried out in 54 eyelids of 49 patients with involutional entropion.

\section{RESULTS}

There were $28(57 \%)$ females and $21(43 \%)$ males. The mean age was 73.5 years (range 46-91) and were followed up from between $1 / 2$ to 60 months (mean $30.25)$. Four (7.4\%) cases were bilateral and repeat procedure using this technique was done in $3(5.6 \%)$ cases when the first surgery using a different method (Weis and Wheeler) had earlier failed. Complications were few as only two cases (3.7\%) had slight peaking and these resolved after a few weeks. One (1.9\%) had slight over correction and there was one $(1.9 \%)$ recurrence. This was one of the primary procedures.

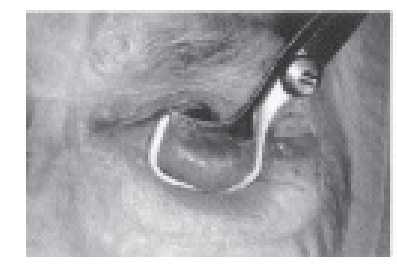

1. Entropion clamp in lower lid

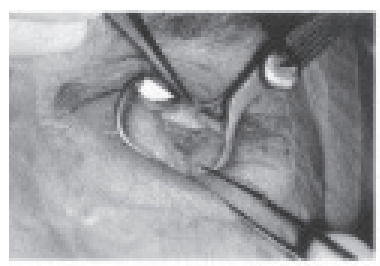

4. Tarsal plate behind muscle

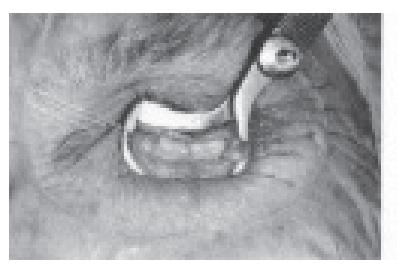

7. Base-down wedge resection of tarsal plate

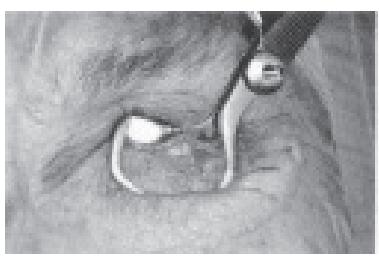

10. Muscle anchored to tarsal plate

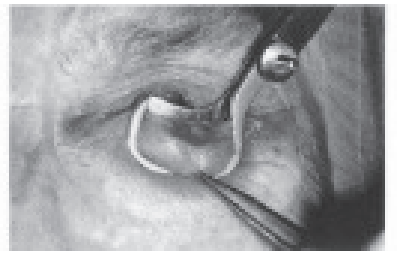

2. Skin incision $2 \mathrm{~mm}$ below lid margin

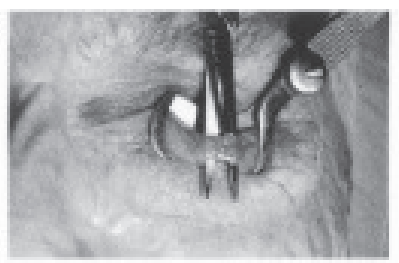

5. Orbicularis oculi strip

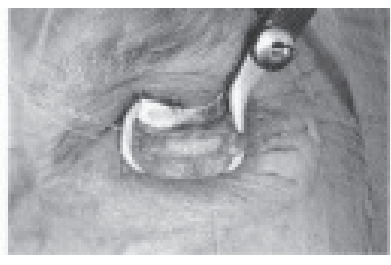

8. Tarsal plate sutured end to end

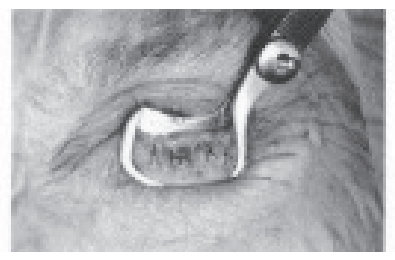

11. Skin sutures with $7-0$ black silk

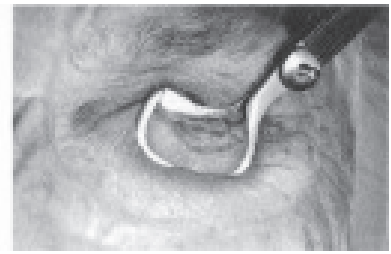

3. Orbicularis oculi is exposed

6. Muscle strip cut into two

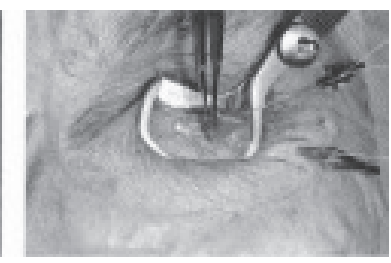

9. Muscle strip overlapped and tied

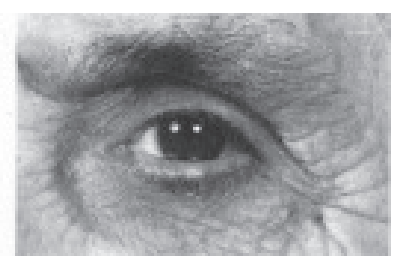

12. Two months post-operative

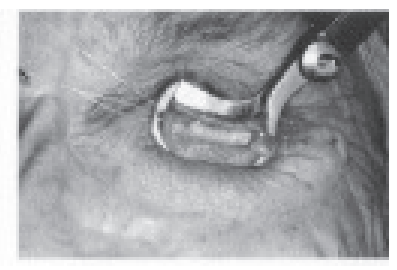

Figure: Stages in the Combined Wheelers and Wedge Resection of Tarsal Plate. 


\section{DISCUSSION}

Various surgical techniques s, $^{2,8,8}$ remain in use for treating lower eyelid involutional entropion because of the complex aetiopathogenesis and the difficulty of one technique addressing all the causes at the same time. Wheeler ${ }^{10}$ in his 1938 paper described his technique of correcting the preseptal orbicularis muscle override in involutional entropion by transposing a strap of muscle from the infratarsal area to the orbital rim. Bick $^{11}$ on the other hand did a fullthickness eyelid shortening to address the problem of horizontal lid laxity. Each method has its shortcoming as the former did not correct the horizontal lid laxity and the latter the orbicularis override. None corrected the eyelid retractor dehiscence.

In the technique used for our patients, the basedown triangular resection of the tarsal plate ensured that shortened this way, the tarsal plate does not rotate on its horizontal axis. The preseptal orbicularis was dissected away from the tarsus, shortened and then anchored to the tarsal plate. This prevented override.

Leone $^{12}$ described a similar technique but the incision was transconjunctival and hence the anterior lamellar scar created with a skin incision, a vital aspect of a successful entropion correction was lacking. In the technique described by Saunders and co-workers, ${ }^{5}$ where a base down triangular full thickness eyelid excision was done, a recurrence rate of $3.4 \%$ was recorded. Here, the preseptal orbicularis muscle was not dissected away from the tarsal plate before shortening and anchorage was done.

The only recurrence recorded was when the technique had not yet been perfected. Our technique did not address the problem of eyelid retractors dehiscence. However, although it is agreed that lower eyelid retractors dehiscence plays a role in the aetiology of entropion, ${ }^{5,13}$ the exact role is not well defined and this factor is not always present. Thus despite our concentration on the other two aetiological factors alone, only one recurrence was recorded during the period under review.

\section{Summary}

Entropion repair using this technique is simple, complications are few and the results very good. Therefore, this is now our preferred method.

\section{REFERENCES}

1. Heidin A. Senile Entropion. Cure rate by retractor tightening and horizontal shortening. Acta Ophthalmologica Scandinavica 1997; 75: 443-6.

2. Weis F A. Spastic Entropion. Trans Am Acad Ophthalmol-Otolaryngol 1995; 59: 503-6.

3. Bleyen I, Dolman PJ, The Wies procedure for the management of trichiasis or cicatricial entropion of either upper or lower eyelids. Br J Ophthalmol 2009. Jul 1(Epub ahead of print).
4. Quickert MH, Rathburn E. Suture repair of Entropion. Arch Ophthalmol. 1971; 85: 503-6.

5. Saunders D H, Shannon G M, Nicolitz E. The Concrib repair of senile entropion. Ophthalmic Surgery 1980; 11: 128-30.

6. Joseph A, Mauriello Jnr, Abdelsalam A. Modified Concrib (Inverted T) procedure with Quickert suture for repair of Involutional entropion. Ophthalmology 1997; 104: 504-507.

7. HSU WM, Liu D. A new approach to the correction of involutional entropion by pretarsal orbicularis muscle fixation. J of Ophthal. 1985; 100: 802-5.

8. Kakizaki H, Zako M, Iwaki M. Posterior layer advancement of the lower eyelid retractor in involutional entropion repair. Ophthal Plast Reconstr Surg. 2007; (4): 292-2.

9. Scheepers MA, Singh R, James N, Zuercher D, Gibson A, Catey B et al. Randomized controlled trial comparing everting sutures with everting sutures and lateral tarsal strip for involutional entropion. Ophthalmology 2009 Oct.27 (Epub ahead of print).

10. Wheeler JM. Spastic entropion correction by orbicularis transplantation. Tran Am Ophthalmol. 1938; 36: 157-162.

11. Bick M W. Surgical management of orbital tarsal disparity. Arch Ophthalmol. 1966; 75: 386-389.

12. Leone C R. Internal tarsus -orbicularis resection for senile spastic entropion. Arch Ophthalmol. 1975; 7: 1004-1006.

13. Hawes MJ, Dortzbach RK. The microscopic anatomy of the lower eyelid retractors. Arch Ophthalmol 1991; 98: 1250-1256. 